\title{
PERFormanCE MeASUREMENT OF THE D-CLASS AUDIO AMPLIFIER
}

\author{
Martin Pospisilik, Jiri Kasacek, Michaela Mikulicova, Milan Adamek
}
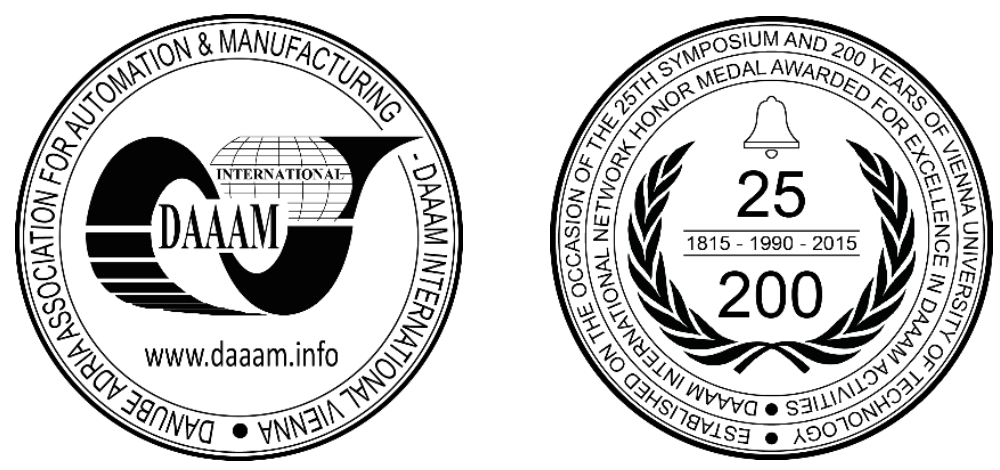

This Publication has to be referred as: Pospisilik, M[artin]; Kasacek, J[iri]; Mikulicova, M[ichaela] \& Adamek, M[ilan] (2018). Performance Measurement of the D-Class Audio Amplifier, Proceedings of the 29th DAAAM International Symposium, pp.0267-0272, B. Katalinic (Ed.), Published by DAAAM International, ISBN 978-3-90273420-4, ISSN 1726-9679, Vienna, Austria

DOI: $10.2507 / 29$ th.daaam.proceedings.038

\begin{abstract}
Class-D audio amplifiers seem to be a perspective way of development of electronics as they can obtain excellent power efficiency together with good performance characteristics. Moreover, they can be easily integrated on a single chip, resulting in clear, comprehensive and non-reckless construction of the audio amplifier. Because the power efficiency is considerably high, some designs even do not need any heat sink, since the heat dissipation can be fully provided by the chip package. In this paper a construction of such an amplifier, being based on the integrated circuit TPA3122, is described. This construction has been developed at Tomas Bata University in Zlin, using conventional component base. Moreover, the paper provides a comparison of the measured performance of the amplifier to the theoretical values provided by the manufacturer of the chip.
\end{abstract}

Keywords: D-class; audio amplifier; power efficiency; power consumption; output power

\section{Introduction}

The Class-D amplifiers are also widely known as "PWM amplifiers", "switching amplifiers" or even the "digital amplifiers". Although they are intended for power amplification of audio signals, compared to the conventional linear amplifiers, their principle of operation differs greatly. While the linear amplifiers only adapt the processed signal to the required level and impedance of their load (usually loudspeakers or headphones) by employing their devices in linear mode of their operation, the Class-D amplifiers do the same using pulse width modulation technique.

A block diagram of a generic class-D amplifier is depicted in the Figure 1. The actual level of the driving signal is compared with a triangular signal, generated inside the amplifier, which results in occurrence of rectangular pulses, the proportions of whose are in relevance to the level of the driving signal. These pulses are further processed by drivers of the output transistors. Because the transistors are operated in the switching mode, their power dissipation is minimized. For these purposes, MOSFET transistors are usually employed. Their great advantage is that when in "on" state, their resistance is considerably low, resulting in very low power dissipation. When turned "off", they are not flown by the electric current so the power dissipation is also negligible. 
In fact, most of the power dissipation occurs during the time of their switching between the "on" and "off" states, as this operation consumes a short period of time in which the resistance of the transistor's channel is increasing or decreasing, i.e. there is current and voltage present at the same time, resulting in joule heat loss. At the output of the amplifier, there is an LC filter, acting as an integrator. Its purpose is to suppress the rectangular pulses and restore the analogous driving signal. This happens because the proportions of the rectangular pulses vary in time, resulting in fluctuating component that occurs at the back end of the filter. Most of the designs also utilize a feedback circuit that helps the amplifier to keep the DC component of the signal at the required level. A detailed description of the waveforms that occur inside the Class-D amplifier is depicted in the Figure 2.

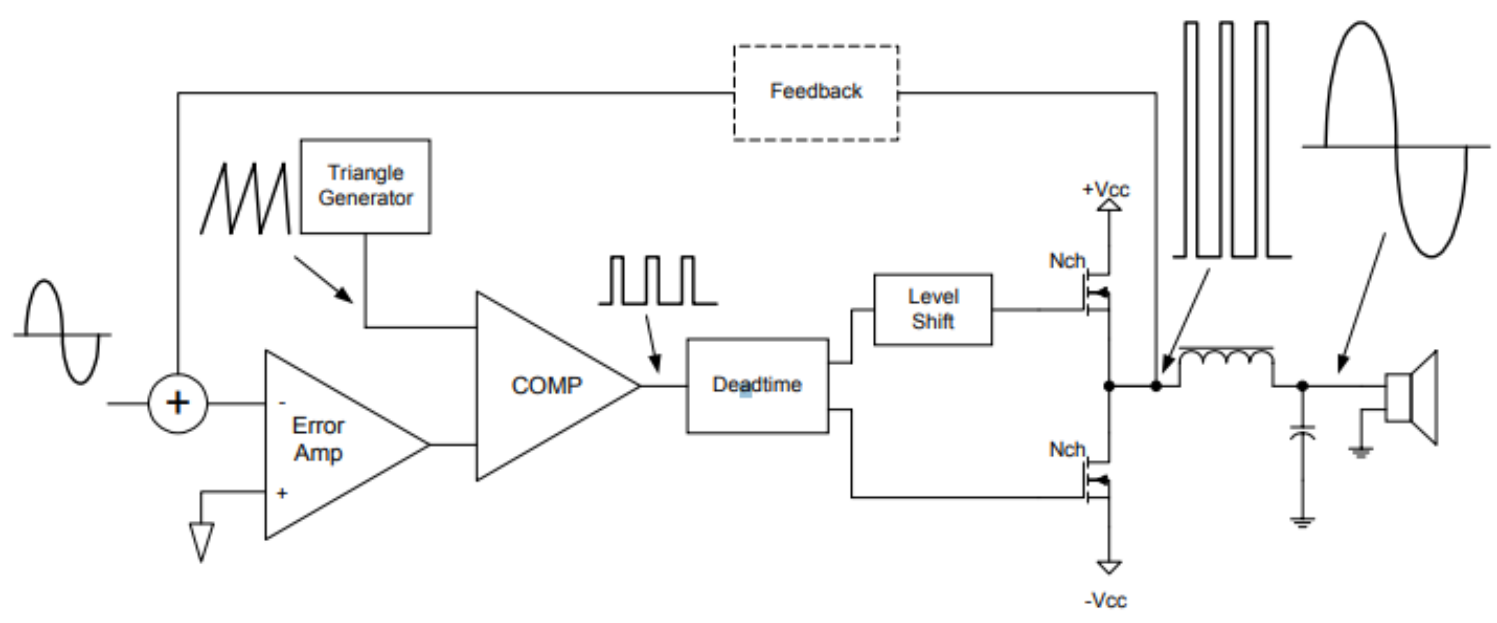

Fig. 1. Generic Class-D amplifier [1]

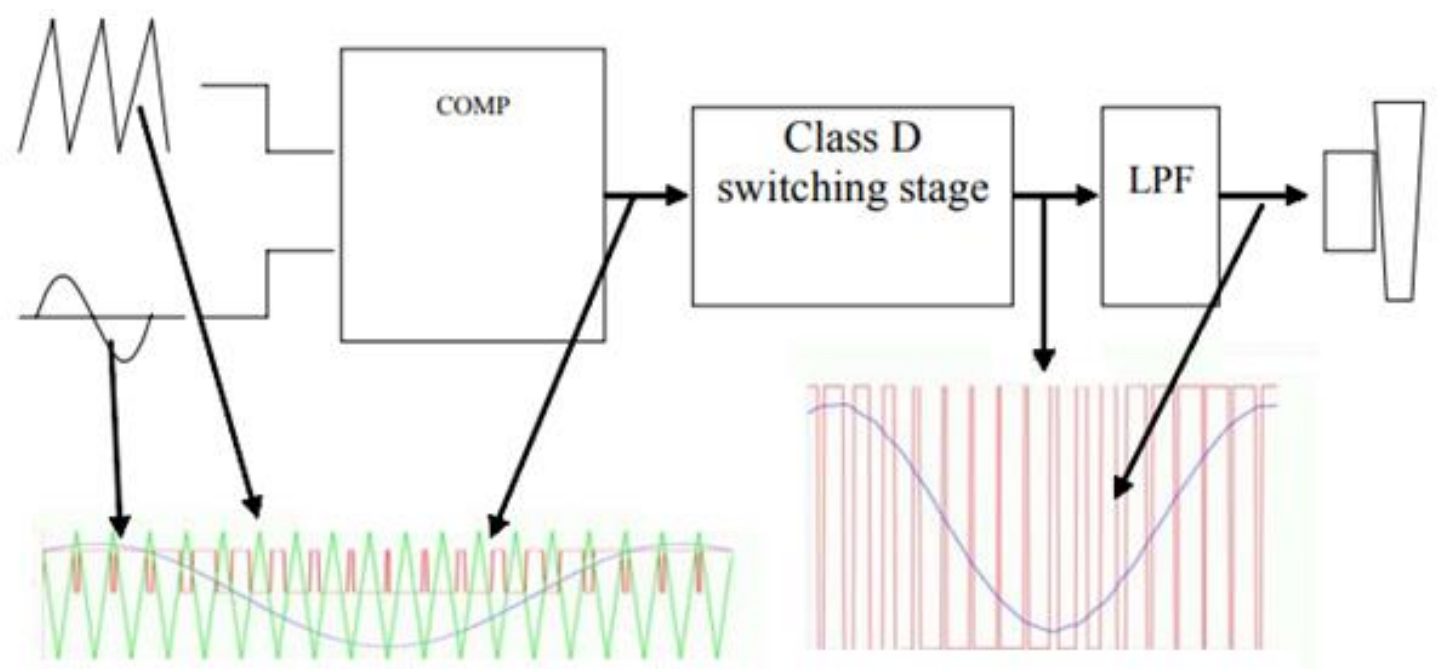

Fig. 2. Detailed description of the waveforms occurring in the Class-D amplifier [1]

As stated above, the most significant advantage of the Class-D amplifiers is their power efficiency. While the highest theoretical efficiency of the conventional Class-AB amplifiers is no higher than approximately $60 \%$ [1,2], the Class-D amplifiers can reach the efficiency up to $95 \%$ [1]. When no high output powers are required, almost the whole amplifier can be integrated on a single chip, not even requiring additional heat sink.

The main disadvantage is based primarily on the fact that the signal is sampled with the operating frequency of the amplifier. Therefore, the frequency range of the driving signal must be limited by means of an antialiasing filter. The discontinuous operating principle may also result in worsened response to step changes of the driving signal, and, moreover, the existence of various signals with steep edges inside the circuitry of the amplifier may lead to undesirable interferences, resulting in decreased signal-to-noise ratio or troubles in the field of electromagnetic compatibility. Single chip solution, described of this paper, also limits the performance of the whole by the parameters of the currently applied integrated circuit. 
This paper shows performance of the amplifier constructed on the basis of a single chip amplifier TPA3122 and provides the comparison of the really measured values with parameters declared by the manufacturer.

\section{A single chip Class-D amplifier TPA 3122}

As stated above, there exist single chip solutions, enabling to create a simple and power efficient Cass-D amplifier by adding only a few components that cannot be integrated in a single package. One of the representatives of such a group is the integrated circuit TPA 3122. Its application, recommended by the manufacturer, is depicted in the Figure 3.

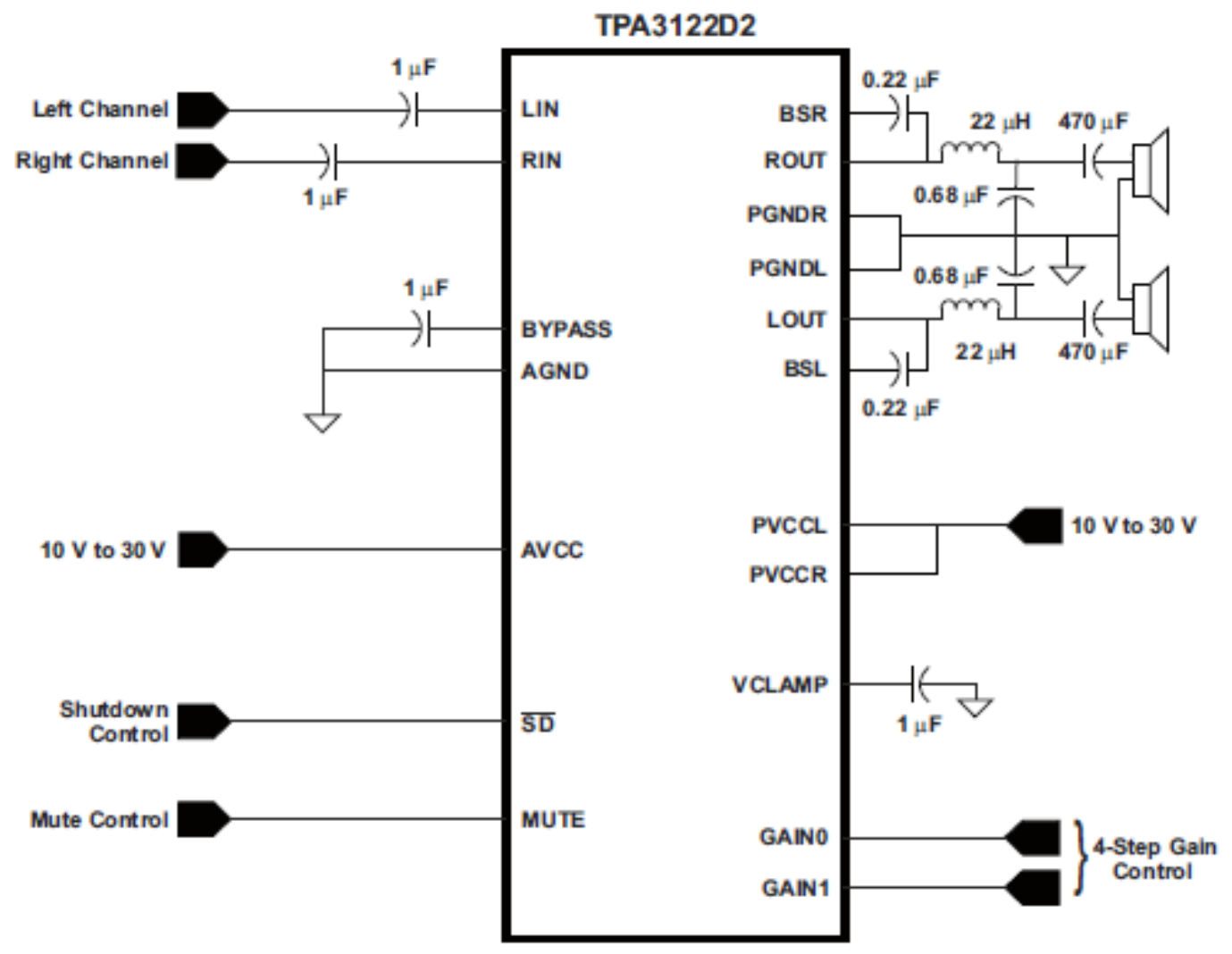

Fig. 3. Recommended application diagram of the integrated circuit TPA 3122D2 [3]

The operation voltage of the integrated circuit is 10 to $30 \mathrm{~V}$, according to the expected load. When loaded by $4 \Omega$, the amplifier should deliver the output power of $10 \mathrm{~W}$ per channel when supplied with the voltage of $17 \mathrm{~V}$. $15 \mathrm{~W}$ per channel are expected when the load is as high as $8 \Omega$ and the power supply voltage is $28 \mathrm{~V}$. The gain of the amplifier may be selected by two gain select pins. The supported gains are 20, 26, 32 and $36 \mathrm{~dB}$.

Because the circuit operates with non-symmetrical power supply voltage, decoupling capacitors must be used at the front-end and the back-end of the chip. The recommended capacity of the front-end capacitors is $1 \mu \mathrm{F}$ while the backend capacitors should have the capacity of $470 \mu \mathrm{F}$. Both, the front-end and the back-end capacitors define the lower roll-off frequency. The upper roll-off frequency is given by the devices of the output LC filter. In the circuit depicted in the Figure 3, the inductances of $22 \mu \mathrm{H}$ and the capacities of $0.68 \mu \mathrm{F}$ are prescribed. However, the values of the supplementary devices may be changed in order to adapt the circuit to the desired operating conditions. More information may be found in the appropriate datasheet [3].

\section{Constructed sample}

In order to perform measurements to be compared with the manufacturer's data, the hereby described amplifier has been constructed and measured. In contrast to the Figure 3, certain changes were made in the wiring diagram in order to adapt the amplifier to the $8 \Omega$ load which enables to reach higher output power. The final wiring diagram is depicted in the Figure 4. As the amplifier is operated in the switching mode, EMC phenomena have been considered [4, 5, 7] as well as heat transfer problems $[6,8]$.

The power supply voltage is blocked by means of local blocking capacitors C7 to C12. The gain of the amplifier is set to $20 \mathrm{~dB}$ by connecting the pins 14 and 15 with the ground. With this setting, the input impedance is $60 \mathrm{k} \Omega$, resulting in the low roll-off at the frequency of approximately $40 \mathrm{~Hz}$, when the capacity of the capacitors C1 and C2 is 1 $\mu \mathrm{F}$. For single ended connection and $8 \Omega$ load, the inductance of the output inductor as high as $47 \mu \mathrm{H}$ is recommended, as well as the capacitance of the filtering capacitors should be $390 \mathrm{nF}$. In this construction, this is achieved by connection of the capacitors $\mathrm{C} 15$ and $\mathrm{C} 16$, resp. C17 a C18 in parallel. 
The pictures of the constructed sample are depicted in the Figure 5.
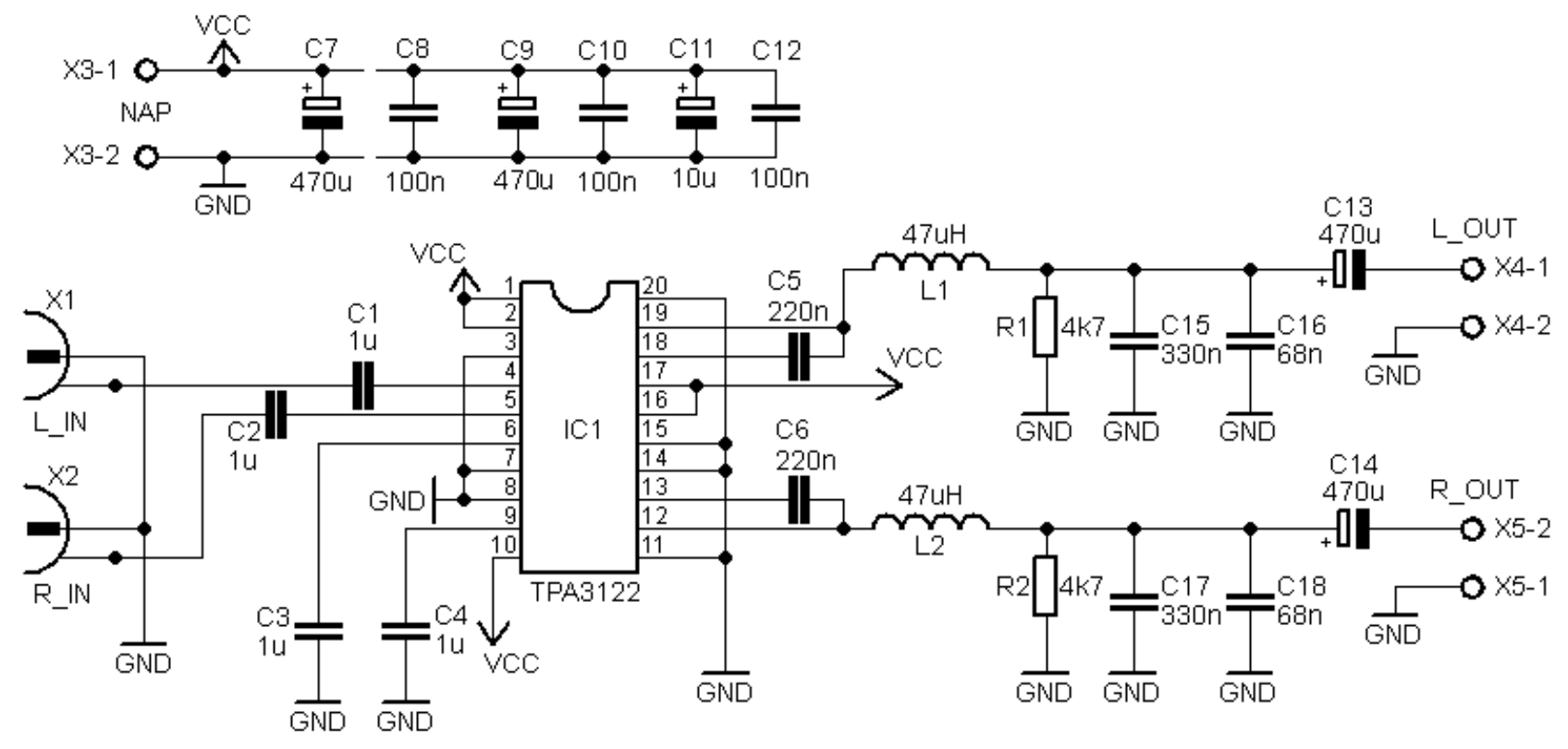

Fig. 4. Circuit diagram of the constructed amplifier
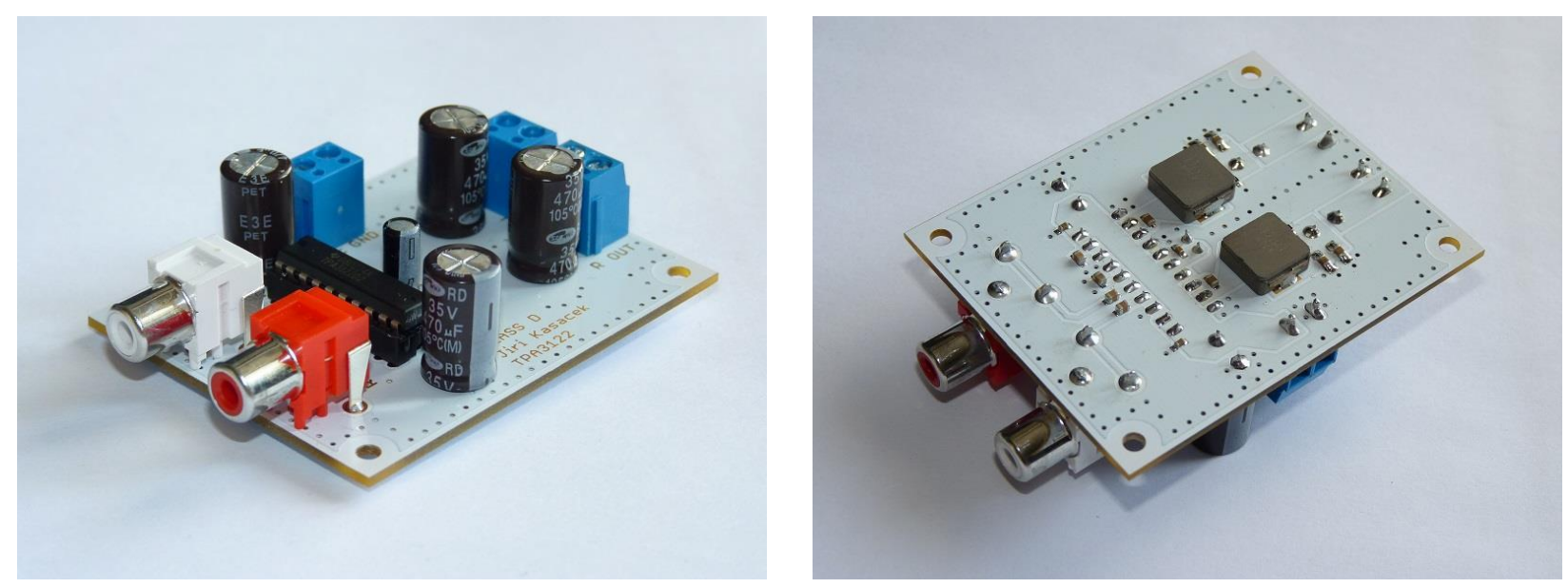

Fig. 5. Pictures of the constructed sample

\section{Performance comparison}

The comparison of theoretical and really measured parameters was performed in the following ways:

- Output power versus power supply voltage.

- Frequency response.

- Crosstalk at the frequency of $1 \mathrm{kHz}$.

The measurement was made with the aid of the following instrumentation:

- Signal generator,

- Oscilloscope,

- Programmable power supply source,

- Resistors $20 \mathrm{~W}$,

- The amplifier.

The comparison of the measured parameters with the data published in the datasheet by the integrated circuit's manufacturer is provided in the subchapters below. 


\subsection{Output power versus power supply voltage}

The output power was measured by means of an oscilloscope. Due to the lack of the distortion meter, the maximum output level was determined in the following way: The total harmonic distortion is, at the maximum output level, mainly given by the amplitude limitation. When the limitation begins to be observable on the oscilloscope's screen, the estimated THD is usually approximately $1 \%$. Sometimes, the amplifier manufacturers tend to specify the output power at the distortion of $10 \%$. In this case, the signal is clipped quite heavily, but the portion of the output power is higher, even with the amplitude did not increase due to the clipping. This is because the output power is given by the area below the signal curve and this area is higher for rectangular shape of the signal rather than in case of harmonic signal. However, since the $1 \%$ point is detectable as it is at the limit of detection by human's eye, the $10 \%$ THD is not easy to identify from the oscillogram. Therefore the output power was measured at the point where the $1 \%$ THD was expected to occur. The measurement was processed using the $1 \mathrm{kHz}$ driving signal the level of which was increased until smooth clipping occurred at the screen of the oscilloscope. Afterwards, the output power delivered to the appropriate load was calculated. With the $8 \Omega$ load, the generator did not provide sufficient output level to drive the amplifier to higher output power than approximately $7 \mathrm{~W}$.

In the Figure 6, the graphs showing output power versus the power supply voltage provided by the producer of the integrated circuit are depicted.
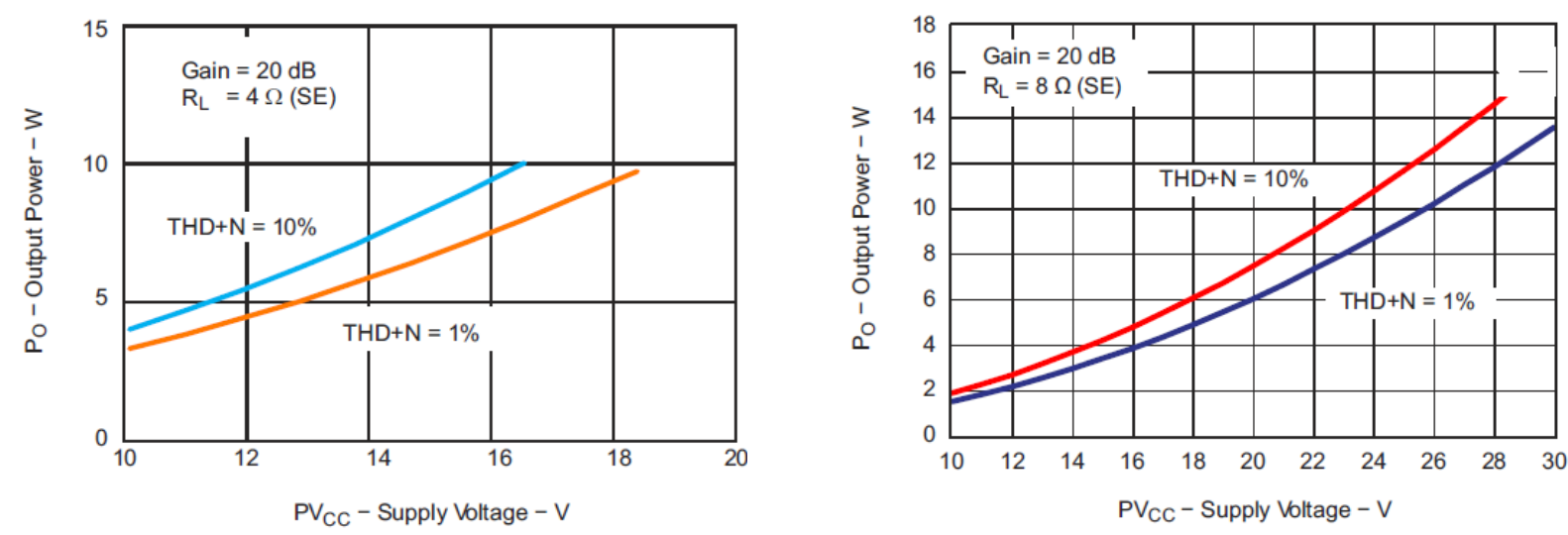

Fig. 6. Output power declared by the manufacturer. Left $-4 \Omega$ load, right $-8 \Omega$ load [3]
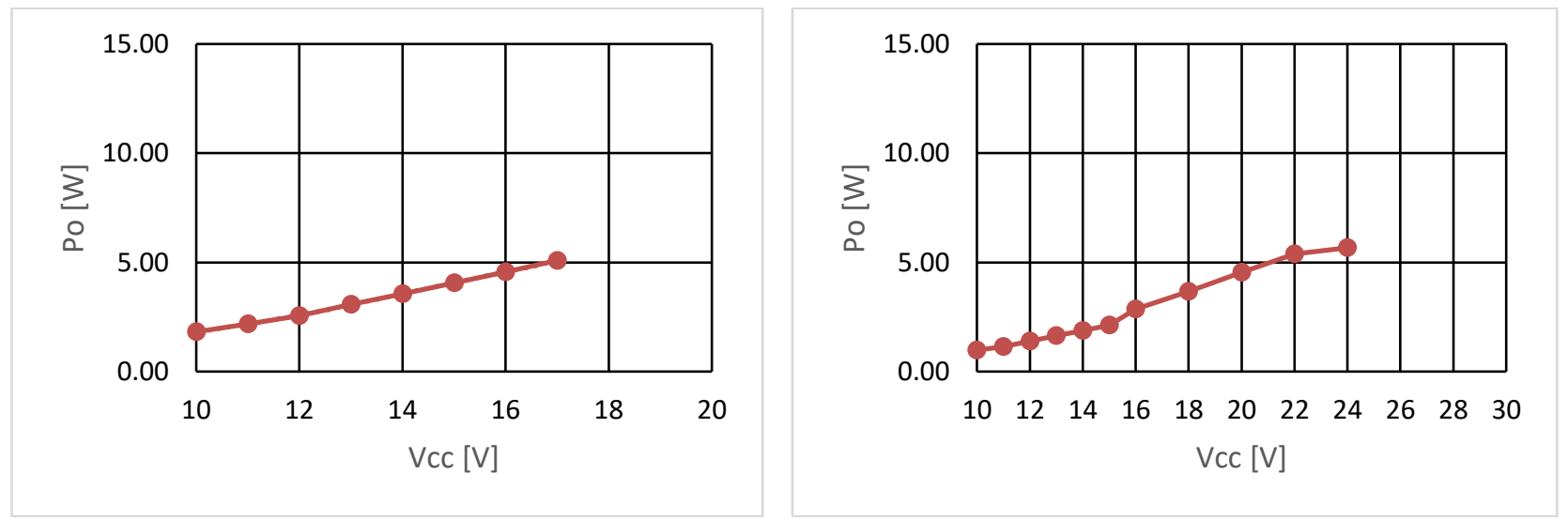

Fig. 7. Output power measured on the hereby presented sample. Left $-4 \Omega$ load, right $-8 \Omega$ load

The graphs depicted in the Figure 7 show that in reality, the output power without detectable clipping is slightly lower than the values declared by the manufacturer of the integrated circuit.

\subsection{Frequency response}

The frequency response graphs are not directly provided by the manufacturer. However, in order to achieve $40 \mathrm{~Hz}$ lower roll off frequency and sufficiently high higher roll off frequency, the values of the appropriate devices are recommended in the integrated circuit's specification. The frequency response of the circuit was measured and the results are depicted separately for both loads, $4 \Omega$ and $8 \Omega$, in the Figure 8 . 

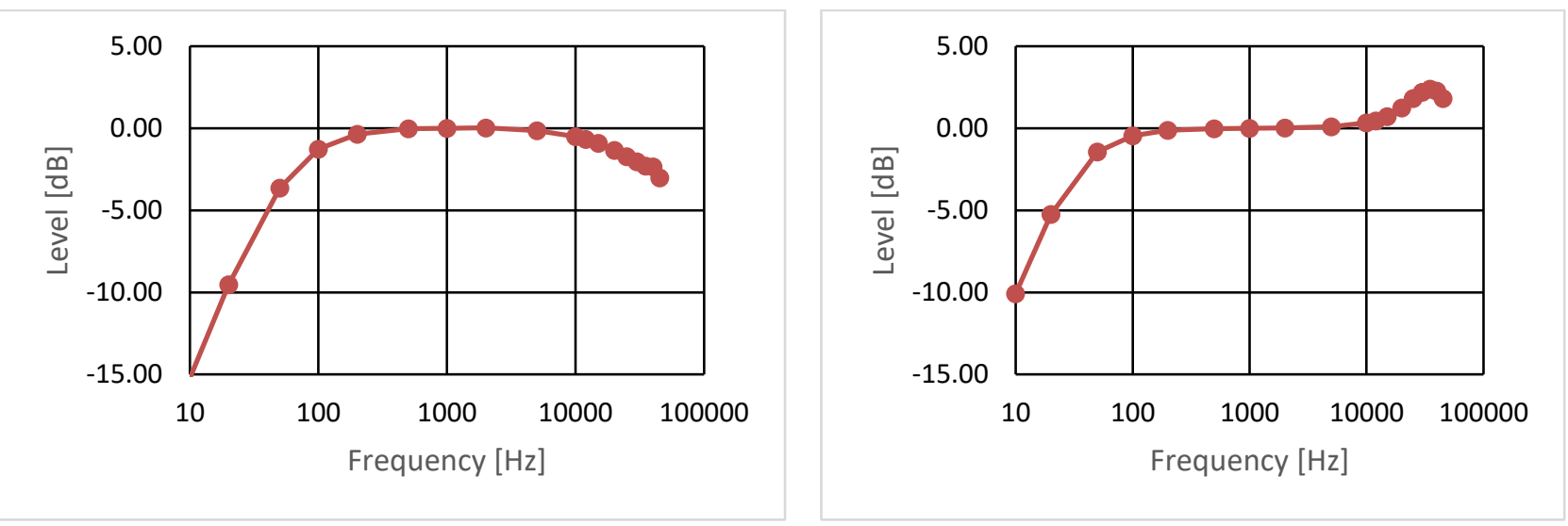

Fig. 8. Frequency response measured on the hereby presented sample. Left $-4 \Omega$ load, right $-8 \Omega$ load

\subsection{Crosstalk at the frequency $1 \mathrm{kHz}$}

The crosstalk between left and right channel has been measured at the frequency of $1 \mathrm{kHz}$. Although the manufacturer declares the typical crosstalk to be as low as $-60 \mathrm{~dB}$, the measured value was approximately $-45 \mathrm{~dB}$.

\section{Conclusions}

Class-D audio amplifiers seem to be a perspective way of development of electronics as they provide high power efficiency together with the possibility of integration and device dimensions diminishing. It is therefore not a surprise that integrated circuits manufacturers have included suitable drivers or whole amplifier solutions in their production program. One of such circuits is TPA 3122 by Texas Instruments. Within this paper, a description of the sample constructed on the basis of this integrated circuit is provided as well as comparison of several parameters measured on the sample with the "typical" values given by the manufacturer.

Namely, output power versus power supply voltage was measured as well as the frequency response and crosstalk between the channels. In all measurements, the measured values were close to the values declared by the manufacturer, however, they were not as optimistic as declared in the appropriate datasheet. Therefore there exist potential to improve the design, mainly by utilizing external power transistors with low on-state resistance and better decoupling capacitors.

\section{Acknowledgments}

This paper is supported by the Ministry of Education, Youth and Sports of the Czech Republic within the National Sustainability Programme project No. LO1303 (MSMT-7778/2014) and also by the European Regional Development Fund under the project CEBIA-Tech No. CZ.1.05/2.1.00/03.0089.

\section{References}

[1] Infineon Technologies. (2005). Class D Audio Amplifier Basics. Online at: http://nf.duseknet.com/vykon.htm

[2] Gaalaas, E. (2006). Class D Audio Amplifiers: What, Why, and How. Online at: http://www.analog.com/library/analogDialogue/archives/40-06/class_d.pdf

[3] Texas Instruments. (2007). TPA 3122D2 datasheet. Online at: http://www.ti.com/lit/ds/symlink tpa3122d2.pdf

[4] Kotisa, Z. (2001). NF zesilovace 1. BEN Technicka literatura, ISBN 80-730-0030-X, Prague

[5] Janku, P.; Pospisilik, M. \& Dulik, T. (2016). Compact Step Down Voltage Converter Constructed in Terms of EMC, Proceedings of the 27th DAAAM International Symposium, pp.0514-0523, B. Katalinic (Ed.), Published by DAAAM International, ISBN 978-3-902734-08-2, ISSN 1726-9679, Vienna, Austria, DOI: 10.2507/27th.daaam.proceedings.077

[6] Marek, V[aclav] (2016). Basic Research of Thermal Transfer Simulations, Proceedings of the 27th DAAAM International Symposium, pp.0578-0585, B. Katalinic (Ed.), Published by DAAAM International, ISBN 978-3902734-08-2, ISSN 1726-9679, Vienna, Austria, DOI: 10.2507/27th.daaam.proceedings.085

[7] Skocik, P[etr] \& Korbel, J[iri] (2017). Assessment of Shielding Effectiveness and Percolation Threshold of Composite Materials, Proceedings of the 28th DAAAM International Symposium, pp.0054-0062, B. Katalinic (Ed.), Published by DAAAM International, ISBN 978-3-902734-11-2, ISSN 1726-9679, Vienna, Austria, DOI: 10.2507/28th.daaam.proceedings.007

[8] Matusu, R[adek]; Pekar, L[ibor] \& Korbel, J[iri] (2017). Robust Stabilization of a Heating-Cooling System by Using Two Feedback Controllers: a Numerical-Graphical Analysis, Proceedings of the 28th DAAAM International Symposium, pp.0194-0198, B. Katalinic (Ed.), Published by DAAAM International, ISBN 978-3902734-11-2, ISSN 1726-9679, Vienna, Austria, DOI: 10.2507/28th.daaam.proceedings.026 